Article

\title{
Qualitative Analysis of the Occupational Health and Safety Performance of Chinese International Construction Projects
}

\author{
Zhen Lei ${ }^{1,2}$, Wenzhe Tang ${ }^{1, *}{ }^{\mathbb{D}}$, Colin F. Duffield ${ }^{3}$, Lihai Zhang ${ }^{3}$, Felix Kin Peng Hui ${ }^{3} \mathbb{C}$ and \\ Richun You ${ }^{1}$ \\ 1 Department of Hydraulic Engineering, State Key Laboratory of Hydroscience and Engineering, \\ Tsinghua University, Beijing 100084, China; leizthu@126.com (Z.L.); darren19950307@163.com (R.Y.) \\ 2 China Three Gorges International Corporation, Beijing 100033, China \\ 3 Department of Infrastructure Engineering, The University of Melbourne, Parkville, VIC 3010, Australia; \\ colinfd@unimelb.edu.au (C.F.D.); lihzhang@unimelb.edu.au (L.Z.); kin.hui@unimelb.edu.au (F.K.P.H.) \\ * Correspondence: twz@mail.tsinghua.edu.cn; Tel.: +86-10-62794324
}

Received: 11 October 2018; Accepted: 20 November 2018; Published: 22 November 2018

\begin{abstract}
Chinese contractors undertaking international projects are frequently criticized for their poor Occupational Health and Safety (OHS) performance. It is noticed that people with different occupations may perceive OHS differently. From a qualitative perspective, this study investigates the perceived OHS performances of design managers and construction managers engaged in Chinese overseas construction projects, considering a range of subgroups classified by people's overseas experience, project size, project industry, project location, and firm size. The analysis was based on an e-questionnaire survey that sampled responses from 52 design managers and 160 construction managers involved in 110 international projects, and face-to-face interviews with 26 managers. The findings indicate that the assessment variation of OHS performance between design managers and construction managers is not only related to their different mental ways, but also can be mediated by their in-progress communication and affected by project and organizational conditions. The varying OHS performance in projects with different sizes or from different regions also suggests that Chinese contractors should be more proactive in OHS management instead of passively responding to external requirements.
\end{abstract}

Keywords: occupational health; safety; comparative analysis; Chinese contractors

\section{Introduction}

Chinese contractors are playing a significant role in the international construction industry. With competitive project cost and strong specialty expertise, Chinese contractors are achieving a rapid development in international construction markets [1,2]. According to the statistics from China Ministry of Commerce, China's 2015 overseas contracting revenue was $\$ 154$ billion US, while the number was $\$ 8.4$ billion US in 2000 [3]. In the "2016 Top 250 International Contractors" list compiled by Engineering News-Record [4], there were 65 Chinese contractors, greater than the number of any other country in the world.

In the rapid expansion of their overseas business, Chinese contractors are also facing challenges with regard to occupational health and safety (OHS) management. Chinese contractors were criticized for their poor behavior on safety management, such as poor safety awareness, lack of training, limited resource input and reckless operation [5]. Cross-national comparison of construction safety performance also showed that China had a higher fatal construction accident rate than Europe 
and America [6]. The benchmarking analysis about corporate social responsibility perceptions of Chinese international contractors and international prominent contractors from USA, France, Spain, and Germany conducted by $\mathrm{Wu}$ et al. demonstrated Chinese contractors attach lower priority to OHS management [7]. Zou and Zhang investigated construction personnel's safety risk perception comparison in China and Australia, and revealed that China's main safety risks were "human-and procedure-related issues", e.g., lack of safety education and accident prevention procedures, while Australia gave more attention to environmental and site condition risks [8]. This disparity also indicates the relative poor OHS management of Chinese contractors.

In overseas project implementation, there exist two types of occupations in the project team for the Chinese construction companies. One type is design managers, who are responsible for management of design schemes from design companies and providing technical support for construction. Another is construction managers, who are responsible for management of construction activities to ensure the construction meeting requirements of quality, time, cost, and OHS. OHS work is closely related to construction, and can also be affected by design or technical schemes $[9,10]$. It is pointed out that project team members with different occupations may have different perceptions of OHS issues [11-14]. The difference implies potential risks in OHS management and helps provide a deeper understanding of contractor's OHS practice. There is a lack of empirical studies on the qualitative analysis of OHS performance of Chinese contractors with consideration of the potential difference in perceptions between design managers and construction managers.

Thus, from a qualitative perspective, this paper investigates the perceived OHS performance of design managers and construction managers engaged in Chinese overseas construction projects. The study aims to: (1) test whether the perception of OHS performance varies between design managers and construction teams, within a range of subgroups classified by people's overseas working experience, project size, industry sector, project location, and firm size; (2) investigate potential causes of the differences; and (3) provide insights for contractors to improve their OHS performance in international markets. This study helps supplement existing research on the comparison of OHS perceptions from people with different occupations and also contributes to a deeper understanding of the OHS practice of Chinese international contractors.

\section{Literature}

Scholars have noticed that different people may perceive OHS in different ways [10,11,14-19]. Chen and Jin investigated different kinds of workers' perceptions of a safety program conducted by a U.S. contractor on its jobsites, and found that older workers tended to have more positive perceptions than young workers, but the perceptions from workers with high and low safety risks showed no significant difference [14]. On the contrary, Gyekye found workers with high safety risks had negative perceptions relative to workers with low risks when investigating Ghanaian workers' perceptions of workplace safety [19]. Comparing perceptions of safety culture or climate between managers and workers, Gilkey et al. and Marin et al. both found managers scored higher than workers, as they conducted the survey respectively in residential construction in Colorado in U.S. and of Hispanic workers in Massachusetts in U.S. [11,13]. Geminiani et al. concluded contractors' and inspectors' perceptions could be significantly different in terms of the OHS inspectorate performance [18]. Lingard et al. compared four groups (architects, engineers, constructors and OHS professionals) of Australian construction professionals' judgments of accidental injury likelihood by photographic experiment and revealed that no shared mental models exist in construction project teams [12]. Zhao et al. then investigated the four kinds of professionals' construction risk perceptions in U.S. by using the similar experiment method with Lingard et al and found that architects tend to perceive lower probability of incidents, engineers perceive higher probability, and contractors and safety professionals contain similar medium perceptions [10,12].

The perception variation reveals the different intentions, mental ways or characteristics of different people $[12,20]$. People's perception directly tells how they think about the OHS issues 
and can provide a vivid picture about OHS management of the contractors. It helps scholars and practitioners better understand OHS issues, which can further suggest management emphases [21]. Accordingly, focusing on the two occupations of design managers and construction managers of Chinese international contractors, an unknown question is that whether their perceptions of OHS performance in international construction projects are equal.

\section{Research Methodology}

\subsection{Data Collection}

A combination of questionnaire survey and interview was used for data collection. The questionnaire survey targeted design managers and construction managers to investigate their perceptions of OHS practice in overseas projects. By using the questionnaire survey, respondents' qualitative perception of OHS performance was quantified with differing levels. The questionnaire data were used for the statistical comparison between design and construction teams. Information from interviews further provided qualitative views from a variety of managers regarding their OHS practice. These help draw a comprehensive picture of the OHS perception variation between design and construction teams. The research complied with guidelines of Tsinghua University for research ethics.

An e-questionnaire was developed to survey Chinese managers' perceived OHS performance in their engaged overseas projects. Each respondent was asked to answer the questions based on experience in a specific overseas project. General background questions include the project name, contract size, industry and location, and the respondent's occupation in the project and total overseas working experience. Four questions in a five-point Likert scale were used to survey managers' perceptions of OHS process management and the overall OHS performance in international projects. The questions are as follows.

Q1: Do you agree that requirements of laws, regulations and standards regarding OHS were fully considered in design schemes? Response options range from 1-strongly disagree to 5-strongly agree.

Q2: Do you agree that sound OHS management strategies in construction, e.g., input of OHS funds, provision of OHS facilities, allocation of safety managers and emergency planning, was established according to requirements of laws, regulations, the client and the consulting engineer? Response options range from 1 -strongly disagree to 5-strongly agree.

Q3: How do you think the overall performance of occupational health in the project? Response options range from 1-very bad to 5-very good.

Q4: How do you think the overall performance of construction safety in the project? Response options range from 1 - very bad to 5 -very good.

With the approval of company head offices and under the ethics requirements of Tsinghua University, e-questionnaires were sent to 16 Chinese international contractors in October in 2016. Each firm was ask to distribute the survey to design and construction managers with overseas project experience. 223 questionnaires responses were received.

The electronic records associated with the e-questionnaires enabled the time each respondent took to answer the questions to be checked. Responses where an unrealistically short time $(<5 \mathrm{~s})$ was taken to complete the survey were removed from the sample analyzed. In addition, responses which were based on projects that had not started construction were deleted. In total, 11 responses were deleted resulting in a sample size of 212 valid data records of which 52 responses came from design teams and 160 responses were from construction teams. The sample involved 110 international projects.

In the sample, 120 respondents had 1-5 years overseas experience and 92 ones had over five years overseas experience. The distribution by project contract size ( $\$$ million US) is: $\leq 20(5.2 \%)$, $20-50(13.7 \%), 50-100(15.1 \%), 100-500(39.6 \%)$ and $>500(26.4 \%)$. The distribution by project industry is: power $(57.1 \%)$, transportation $(17.0 \%)$, general buildings (14.2\%), water supply $(5.7 \%)$, mining $(3.3 \%)$, and sewerage/solid waste (2.8\%). The distribution by project location is: Southeast Asia $(24.10 \%)$, Islamic Area (27.40\%), Sub-Saharan Africa (27.80\%), and other (20.80\%). According to the contractors' 
2015 overseas contracting revenues (\$ million US), these managers are from: small-sized firms with revenue $\leq 400(38.7 \%)$, medium-sized firms with revenue 400-800 (31.6\%) and large-sized firms with revenue $>800(29.7 \%)$.

To learn Chinese contractors' OHS management practices, face-to-face interviews with 26 managers from six Chinese contractors according to their sizes were conducted. Three of them were large-sized contractors with overseas revenue $>\$ 800$ million US, two of them were medium-sized contractors with overseas revenue $\$ 400-800$ million US, and one was a small-sized contractor with overseas revenue $<\$ 400$ million US. All interviewees were senior managers with rich experience in overseas projects. The interviews were not limited to the OHS discussion but also covered corporate governance, marketing, technology, quality management, etc. The wide variety of interviewees facilitated a comprehensive understanding of OHS management priority and strategies in Chinese contractors. The views from interviewees also provide evidence and explanation for the perception variation between design and construction teams.

\subsection{Data Analysis}

To compare the different perceptions of the design and construction groups a detailed statistical analysis was undertaken. Independent-samples $z$ and $t$ test were used to test the difference between their means on Q1, Q2, Q3, and Q4. Where the sample size was greater than 30, a $z$ test was used [22]. Otherwise, a $t$ test was used. In the $t$ test, whether to use equal-variance $t$ testing or not was decided by running Levene's test for equality of variances. The statistical analyses were undertaken using the commercial software SPSS 24 (International Business Machines Corporation: Armonk, NY, USA).

An overall comparison was carried out first by dividing the data into two groups regarding design and construction teams. Then, the comparison between design and construction teams was performed separately in subgroups regarding different overseas working years, project sizes, project industries, project locations and company sizes. For example, according to these respondents' overseas experience, the whole data was divided into two subgroups of employees with 1-5 years overseas experience and employees with over five years' overseas experience. The comparison between design managers and construction managers was performed in each subgroup. Similarly, regarding project size, the comparison was separately performed in two subgroups of projects with less than $\$ 100$ million US contract size and projects over \$100 million US contract size. Regarding project industry, the comparison was separately performed in two subgroups of power projects and non-power projects. As with project location, the comparison was separately performed in three subgroups of Southeast Asia, Islamic Area and Sub-Saharan Africa. According to their firms' sizes, the comparison also was separately performed in three subgroups of small-sized contractors, medium-sized contractors, and large-sized contractors.

The results were further analyzed and discussed by the comparative analysis with existing literature and by referring to the interviews. The comprehensive analysis helps provide an in-depth understanding of Chinese contractors' OHS practice. The survey results are as follows.

\section{Results}

Mean values of OHS perceptions and the overall comparison between design and construction teams are presented in Figure 1. The differences that are significant are marked by an asterisk. Q1, Q2, Q3, and Q4 were defined in the section of research methodology. 


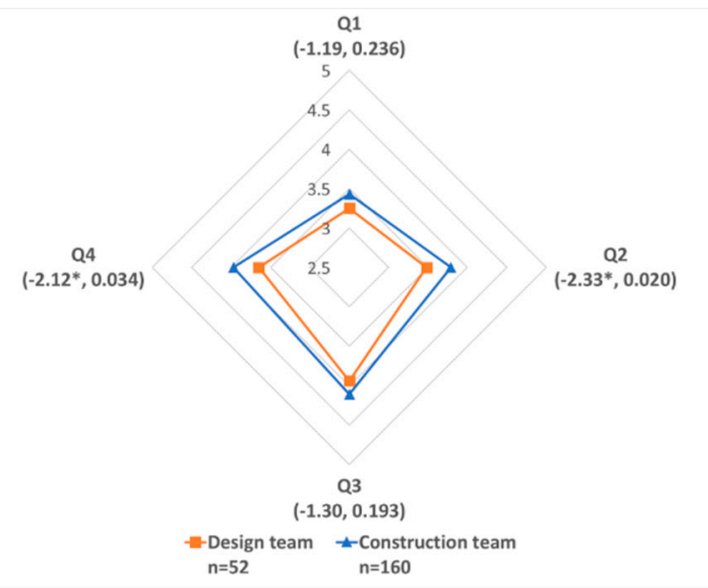

Figure 1. Perception of project OHS performance from design and construction teams. $z$ and $p$ values are shown in the parentheses.

The comparison between design and construction teams in Figure 1 shows that design team gave lower scores of the four questions than construction team, especially on Q2 and Q4 with significant $\mathrm{z}$ values. Perception disparity between design and construction team exists, especially on OHS strategies in construction and the overall occupational health performance. Moreover, the scores of $\mathrm{Q} 1$ are relatively lower than those of the other three questions, indicating that there is not enough consideration of $\mathrm{OHS}$ requirements in design schemes.

Before comparing their difference in different kinds of subgroups by overseas experience, project size, project industry, project location and firm size, the comparison between subgroups by each classification is conducted first to explore whether OHS performance perceptions are equal between people with different overseas experience, different kinds of projects and contractors. The results are shown in Table 1.

Table 1. Comparison of perception of project OHS performance between subgroups.

\begin{tabular}{|c|c|c|c|c|c|c|}
\hline & $\begin{array}{l}\text { The Questions Applied to } \\
\text { Subgroups: M (SD) }\end{array}$ & $\mathbf{n}$ & Q1 & Q2 & Q3 & Q4 \\
\hline \multirow[b]{2}{*}{1} & Managers $1-5$ overseas years & 120 & $3.38(1.00)$ & $3.69(0.82)$ & $4.10(0.78)$ & $3.93(0.86)$ \\
\hline & Managers $>5$ overseas years & 92 & $3.38(0.82)$ & $3.74(0.72)$ & $4.02(0.85)$ & $3.85(0.85)$ \\
\hline \multirow{2}{*}{2} & Projects $\leq \$ 100$ million US & 72 & $3.24(0.81)$ & $3.57 *(0.69)$ & $3.96(0.83)$ & $3.71 *(0.83)$ \\
\hline & Projects $>\$ 100$ million US & 140 & $3.46(0.97)$ & $3.79 *(0.81)$ & $4.12(0.80)$ & $3.99 *(0.86)$ \\
\hline \multirow{2}{*}{3} & Power projects & 121 & $3.50 *(0.94)$ & $3.81 *(0.79)$ & $4.07(0.80)$ & $3.91(0.84)$ \\
\hline & Non-power projects & 91 & $3.22 *(0.88)$ & $3.58 *(0.75)$ & $4.05(0.83)$ & $3.87(0.88)$ \\
\hline \multirow{3}{*}{4} & Southeast Asia & 51 & $3.45(0.97)$ & $3.71 b^{*}(0.67)$ & $4.18(0.68)$ & $3.94(0.86)$ \\
\hline & Islamic Area & 58 & $3.24(0.76)$ & $3.36 a^{*}, c^{* *}(0.69)$ & $3.91(0.73)$ & $3.72(0.77)$ \\
\hline & Sub-Saharan Africa & 59 & $3.54(0.92)$ & $3.83 \mathrm{~b}^{* *}(0.83)$ & $3.95(0.99)$ & $3.90(0.99)$ \\
\hline \multirow{3}{*}{5} & Firms $<\$ 400$ million US & 82 & $3.37(0.91)$ & $3.77(0.77)$ & $4.23 \mathrm{y}^{*}(0.71)$ & $4.11 \mathrm{y}^{* *}, \mathrm{z}^{*}(0.74)$ \\
\hline & Firms $\$ 400-800$ million US & 67 & $3.39(0.90)$ & $3.69(0.80)$ & $3.93 x^{*}(0.89)$ & $3.72 x^{* *}(0.95)$ \\
\hline & Firms $>\$ 800$ million US & 63 & $3.40(0.98)$ & $3.67(0.76)$ & $4.00(0.82)$ & $3.79 x^{*}(0.85)$ \\
\hline
\end{tabular}

Note: $\mathrm{a}=$ compared with Southeast Asia, $\mathrm{b}=$ compared with Islamic Area, $\mathrm{c}=$ compared with Sub-Saharan Africa; $\mathrm{x}=$ compared with Firms $<\$ 400$ million US, $\mathrm{y}=$ compared with Firms $\$ 400-800$ million US, $\mathrm{z}=$ compared with Firms $>\$ 800$ million US; ${ }^{* *}=$ at the significant level of $0.01,^{*}=$ at the significant level of 0.05 .

Comparisons between subgroups in Table 1 show that, (1) no overall significant disparity exists between managers with different overseas experience, (2) large projects have a significantly better occupational health performance than small projects, (3) power projects have significantly better consideration of OHS requirement in design and better OHS strategies in construction than non-power projects, (4) perception of consideration of OHS requirement in design from Islamic Area is significantly 
worse than that from Southeast Asia and Sub-Saharan Africa, and (5) perception of occupational health performance from small firms is significantly higher than that from large and medium firms, meanwhile perception of construction safety performance from small firms is significantly higher than that from medium firms.

These results demonstrate that perception of OHS performance varies according to different kinds of projects and firms. The investigation of whether the OHS perception disparity between design and construction teams vary within these subgroups were further analyzed as follows.

\subsection{Comparison within Subgroups by People's Overseas Experience}

The comparison of OHS perceptions between design and construction teams is carried out separately in two subgroups classified by people's overseas experience. The results are presented in Figure 2.

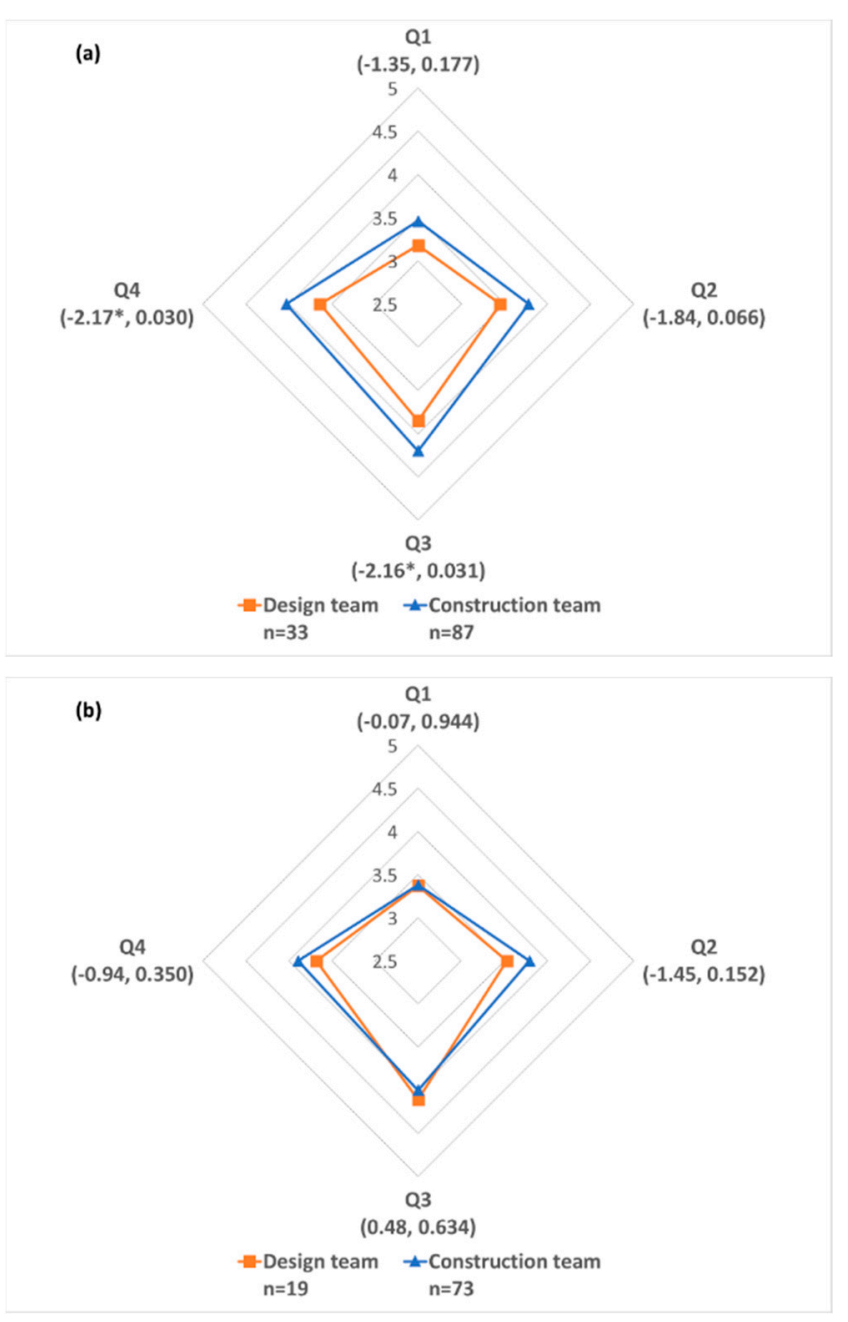

Figure 2. Comparison between design and construction teams in the subgroups by overseas experience: (a) people with 1-5 years overseas experience; (b) people with $>5$ years overseas experience. $z$ or $t$ value and $p$ value are shown in the parentheses.

The results in Figure 2 show that the perception disparity between design and construction teams mainly lies in the subgroup of people with less than five years overseas experience. When these managers get more experience in overseas projects, their perception disparity on OHS performance is not significant. 


\subsection{Comparison within Subgroups by Project Size}

The comparison of OHS perceptions between design and construction teams is carried out separately in two subgroups classified by project size. The results are presented in Figure 3.

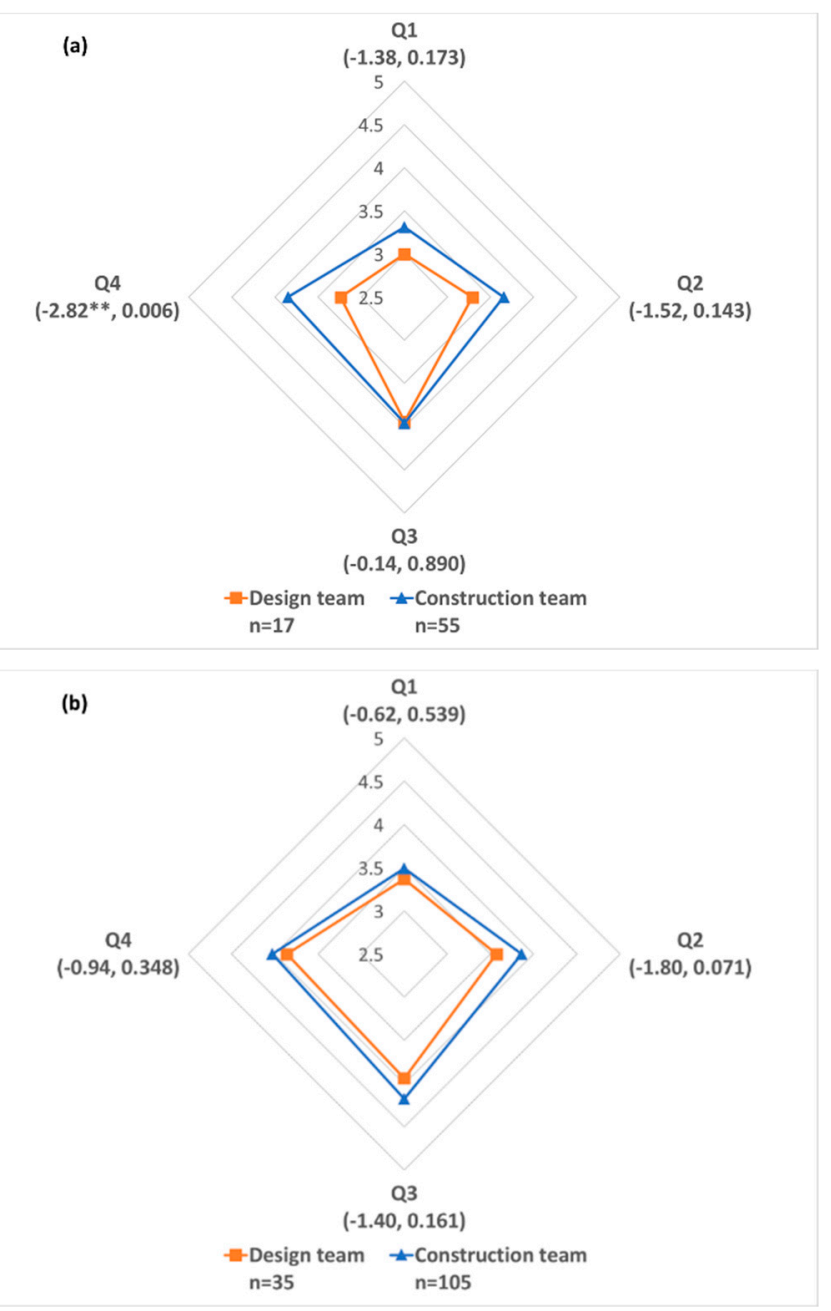

Figure 3. Comparison between design and construction teams in the subgroups by project size: (a) project contract $\leq \$ 100$ million US; (b) project contract $>\$ 100$ million US. $t$ and $p$ values are shown in the parentheses.

The results in Figure 3 show that the perception disparity between design and construction teams mainly lies in projects with contract below $\$ 100$ million US, especially on occupational health performance, while there is no significant difference in larger projects. As project size increases, the disparity between design and construction teams tends be smaller, especially for the perception of occupational health performance.

\subsection{Comparison within Subgroups by Project Industry}

The comparison of OHS perceptions between design and construction teams is carried out separately in two subgroups for power projects and non-power projects. The results are presented in Figure 4. 


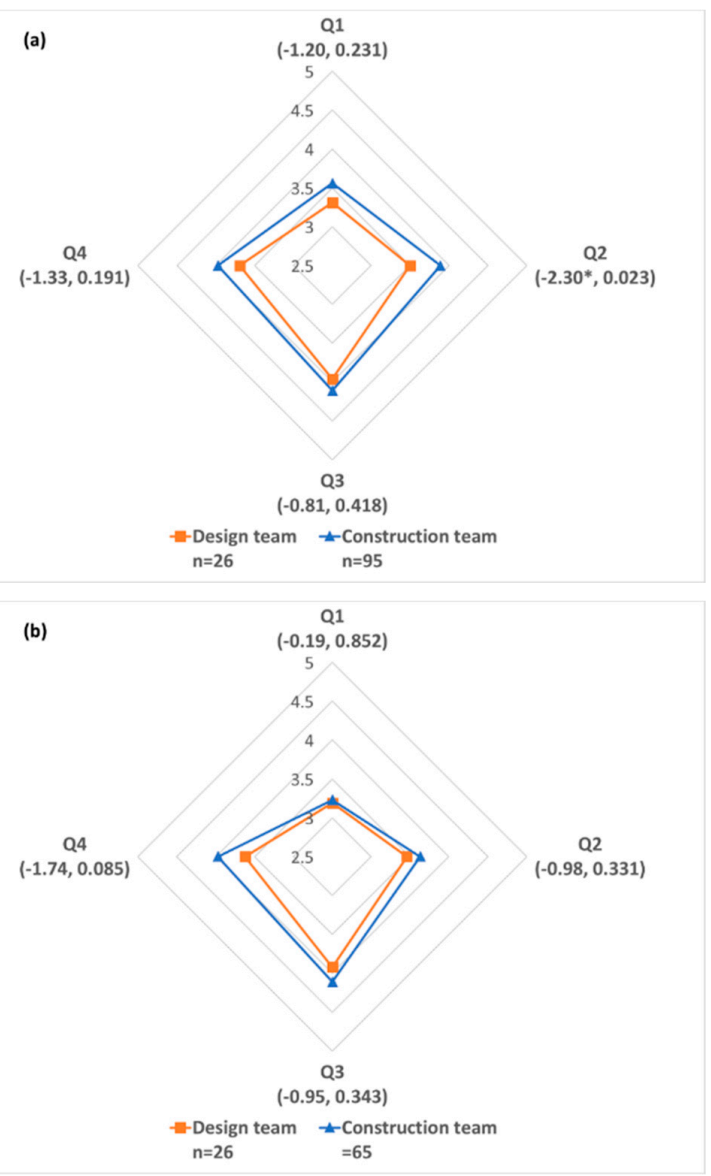

Figure 4. Comparison between design and construction teams in the subgroups by project industry: (a) power projects; (b) non-power projects. $t$ and $p$ values are shown in the parentheses.

The results in Figure 4 show that in power projects, there is significant difference on perception of OHS strategies in construction between design and construction teams, while there is no significant difference in non-power projects. The perception disparity between the two teams is relatively larger in power projects.

\subsection{Comparison within Subgroups by Project Location}

The comparison of OHS perceptions between design and construction teams is carried out separately in three subgroups classified by project location. The results are presented in Figure 5.

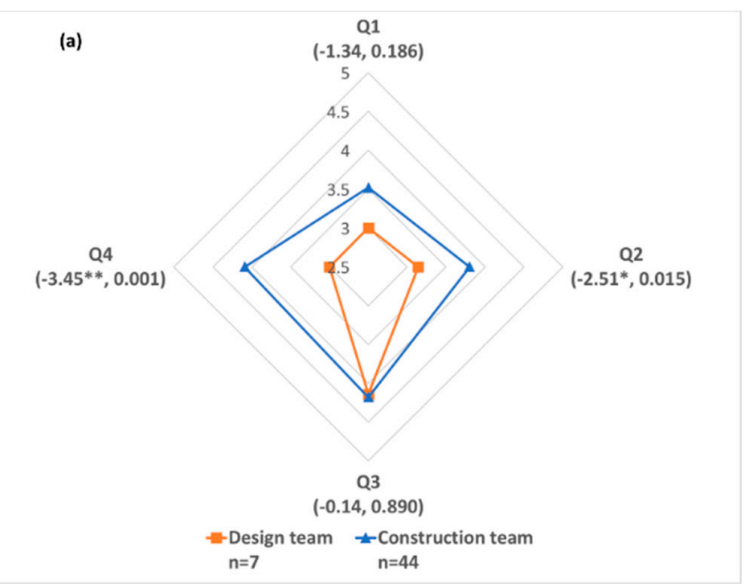

Figure 5. Cont. 


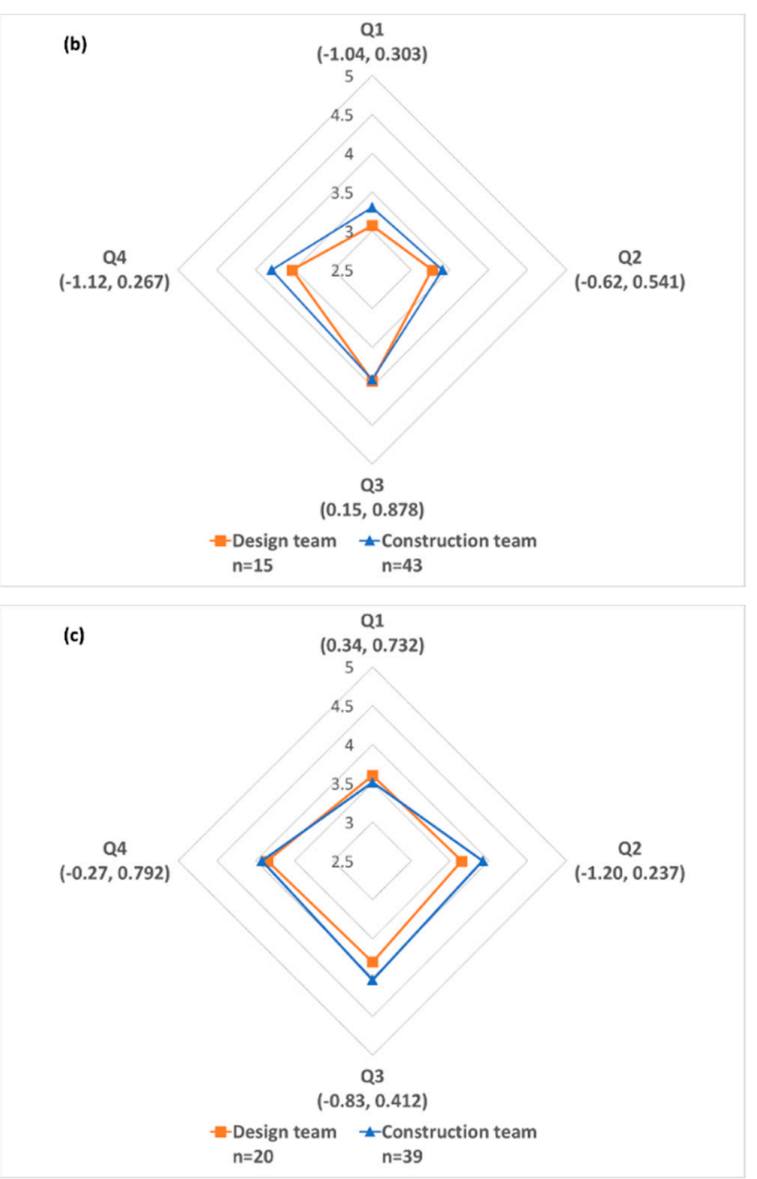

Figure 5. Comparison between design and construction teams in the subgroups by project location: (a) Southeast Asia; (b) Islamic Area; (c) Sub-Saharan Africa. $t$ and $p$ values are shown in the parentheses.

The results in Figure 5 show that the perception disparity between design and construction teams mainly lies in projects located in Southeast Asia.

\subsection{Comparison within Subgroups by Firm Size}

The comparison of OHS perceptions between design and construction teams is carried out separately in three subgroups classified by firm size. The results are presented in Figure 6.

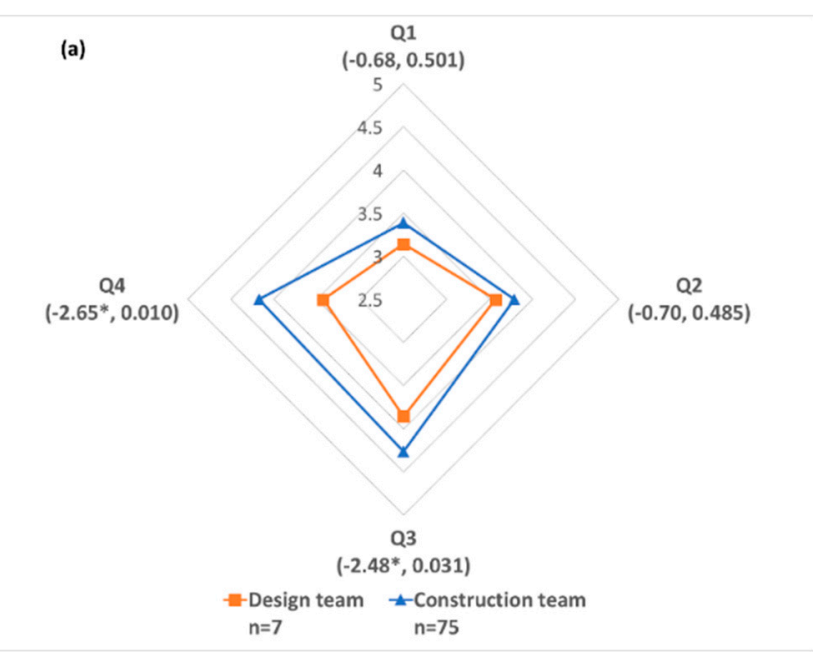

Figure 6. Cont. 


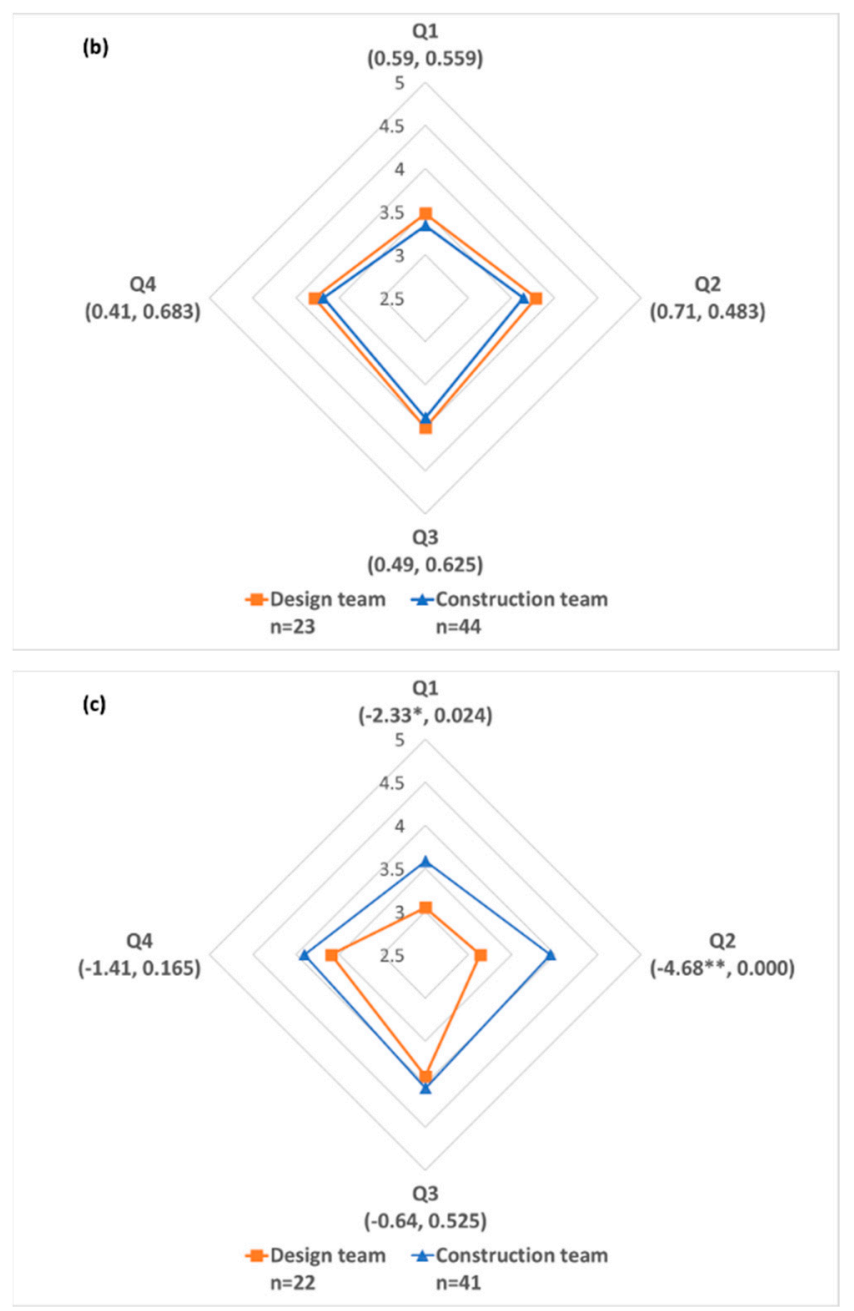

Figure 6. Comparison between design and construction teams in the subgroups by company size: (a) small-sized contractors with overseas revenue $<\$ 400$ million US; (b) medium-sized contractors with overseas revenue \$400-800 million US; and (c) large-sized contractors with overseas revenue > $\$ 800$ million US. $t$ and $p$ values are shown in the parentheses.

The results in Figure 6 show that (1) for large-sized contractors, the perception disparity between design and construction teams mainly lies on Q1 and Q2; (2) for small-sized contractors, the disparity lies on Q3 and Q4; and (3) while for medium-sized contractors, there is no significant difference between the two teams.

\section{Discussion}

In most circumstances, design teams tended to score OHS performance in international projects lower than construction teams (see Figures 1-5). A potential reason for this is that the technical background of design managers tends to make them stricter than construction team members in assessing the OHS performance. This accords with the findings of Zhao et al. where they concluded that design engineers have higher construction risk perceptions than construction professionals [10]. In practice, construction managers are at the front line of OHS management, while at the same time, they also face the pressures of delivering the project to tight schedules and budgets. This can lead to conflicts between productivity and OHS [23]. From the results of this study construction managers from Chinese contractors tend to emphasize productivity over OHS. Wu et al. have pointed out that Chinese contractors are not necessarily proactive and strategic in their management of OHS [7]. An interviewed senior safety manager stated: 
"There are a lot of emergencies in overseas projects. HSE (occupational health, safety and environment) management serves project implementation and doesn't belong to productive input. In most of projects, it is kind of passive management."

One team has a higher perception of OHS risk, while another one does not give enough priority to OHS management. Their perception disparity indicates that potential OHS issues exist and there is room for the contractors to enhance their OHS management.

The results from Figures 1-5 also show that the score of Q1 is lower than that of the other three questions. It appears that OHS requirements are not fully considered in design schemes. This result is owing to that in practice, OHS management tends to be the responsibility of contractors but not designers. Although it is agreed that work in the design stage is also an important factor for OHS performance in construction $[9,24]$, there is still a lack of improvement in OHS through design in the construction industry [25].

\subsection{Overseas Experience}

The perception disparity between design and construction managers mainly lies in the depth of experience (see Figure 2). The difference between the groups was far less as people get more experience. Figure 2 also shows that there is not much difference regarding the mean scores between less-experienced construction team and more-experienced construction team, while the mean scores between design teams is a little different. Less-experienced design team scores a little lower than more-experienced design team. Similarly, Chen and Jin found that older workers tended to have a greater acceptance of their company's safety management than younger workers [14]. A possible cause for this, refer Figure 2 is that, when design managers get more experienced, they become more satisfied with the OHS performance. Meanwhile, the design managers have more communication with the construction managers and understand more about their OHS practice, which helps decrease their perception disparity.

\subsection{Project Size}

The perceptions of occupational health between design and construction teams in small projects is significantly different (see Figure 3). The results indicate that there are more perceived risks about occupational health in small projects. Table 1 also shows that small projects have worse perceived OHS performance than large projects. This is in accordance with Jannadi and Assaf's finding. They assessed safety levels on construction sites of large projects and small projects and found that safety in large projects were better than small projects [26]. Generally, large projects tend to have a better OHS management system as with there are more resource inputs compared with small projects. The contractors also pay more attention to large projects. An interviewed labor union chairman, when asked to introduce their management activities regarding employees' psychological health, said:

"We built 'Staff Home' and held sports and recreational activities. Our people can take exercise and play basketball and table tennis. As for large projects, we also organized many learning and training activities."

When studying factors for occupational injury in a high-speed railway construction project, Bena et al. also found safety risks are higher among workers with shorter contracts [27]. From this perspective, employees in small projects tend to have shorter work contracts and this may lead to a lack of OHS consciousness. In this respect, contractors should pay more attention to OHS in small projects.

\subsection{Industry Sector}

The results in Table 1 demonstrate that power projects have better OHS performance than non-power projects. One possible explanation is that these Chinese contractors are specialized in power construction and have been working on it for decades. However, the OHS perception disparity 
between design and construction teams in power projects is greater than that in non-power projects (see Figure 2). In general, power projects tend to be more complex than non-power projects. Although these Chinese contractors are good at power construction, they should also pay attention to the OHS issues in power projects. A potential management implication is that they could get design team involved in the OHS management.

\subsection{Project Location}

The disparity of OHS perception between the two teams also varies in different regions. The disparity mainly lies in Southeast Asia. This is mainly related to the cultural, governance or institutional differences regarding OHS work in projects among these areas [28]. Manu et al. also pointed out the dire situation of OHS management in emerging countries and investigated OHS practices in Malaysia, Vietnam, and Cambodia [29]. On the whole, the contractors perceived that OHS requirements from clients and governments in Southeast Asia are lower than those in Islamic Area and Sub-Sahara Africa. A marketing director in headquarter of a Chinese contractor delivering projects in Middle East and Africa said:

"In the Middle East, e.g., Saudi Arabia, Kuwait, Dubai, they adopt the most high-end European and American standards and have tough requirements for contractors. In Africa, although with underdeveloped economy, they govern in line with Europe and America and have high requirements for contractors."

A safety director involved in a hydropower in Sudan said:

"HSE requirements in the project are very strict. If found there is oil leakage in equipment, it is required to stop the equipment first and then make a four-step report including (1) the reason, (2) how to deal with it, (3) request for the acceptance of dealing measures and results and (4) subsequent preventive measures."

A chief engineer with two projects experience in Southeast Asia, however, said:

"Occupational health requirements in Southeast Asia is a little weak".

This is in accordance with interviews with two experienced safety managers from the same company:

"In Southeast Asia, like Cambodia and Laos, the clients, government and supervisors basically didn't govern the health and safety management issues of contractors."

In areas with high OHS requirements, like Sub-Saharan Africa and Islamic Area, the disparity between design and construction teams is small, while in the areas with low OHS requirements, the disparity is large. When OHS requirements are strict, the contractors have to pay more attention to OHS management. In dealing with challenges from high OHS requirements, Chinese contractors tend to hire foreign OHS experts for OHS management to meet local requirements. A technical director from Engineering Department of a Chinese contractor said:

"We will hire foreign safety directors, especially in areas with high HSE requirements, to help (1) establish HSE management plan, (2) communicate with clients and (3) make process documents. These safety directors have a high management level equivalent to deputy project manager."

The contractors pay more attention and input more resources to OHS management in these areas. This facilitates a culture of emphasizing OHS on sites, and further helps reduce the two teams' perception disparity on OHS performance.

It shows that OHS management strategies of the contractors depend on the levels of requirements from outside. In essence, it demonstrates the passive OHS management habit of these contractors. When asked about the OHS management strategies, the director of a Chinese contractor's department of safety, quality, and environment said: 
"HSE management's priority is to meet the requirements of clients. It depends on the requirements of clients. Generally, it is kind of passive management."

Chinese contractors should be more proactive and strategic on OHS management in international projects.

\subsection{Contractor Size}

The perceived disparity between design and construction teams is found in large-sized and small-sized contractors, but no significant difference exists in medium-sized firms (see Figure 6). In large-sized contractors, the disparity lies on OHS process management including consideration of OHS requirements in design and OHS management strategies in construction, while in small-sized firms, the disparity lies on the overall performances of construction safety and occupational health. The results indicate the complex relationship between firm size and the two groups' perception disparity.

The disparity lying on OHS process management for large-sized contractors may result from the complex organizational structure and inefficient decision-making procedure in large companies. A deputy general manager of a large-sized contractor said:

"Management system in our firm is norm, but not efficient. The administration system is too huge in state-owned enterprises. Decision making needs a lot of paper work and takes a long time. This on the hand helps make sure the correct decision and improve risk ability, on the other hand would decrease the efficiency and raise the management cost."

This inefficiency may increase design and construction teams' perception disparity on OHS process management.

On the other hand, the perception disparity on overall OHS performances in small-sized contractors is a little strange. Moreover, the results in Table 1 show that the perceptions of the overall OHS performances (Q3 and Q4) from small-sized contractors are greater than those from large-sized contractors and medium-sized contractors. Some studies on the relationship between OHS performance and firm size are as follows:

- Sunindijo claimed that: Large organizations have better safety performance as "they have the resources and leverage to develop and implement robust safety management systems" [30].

- Hasle and Limborg claimed that: Employees from small contractors face higher risks than those from larger ones, as "small enterprises have difficulties in controlling risk" [31].

- Fabiano et al. investigated the relationship between accident frequency and firm size based on industrial data from Italian industry and found that: Accident frequency tends to decrease as firm size increases [32].

- McVittie et al. reviewed records of the Workers' Compensation Board of Ontario data and found that safety performance is better as firm size increases [33].

- Bena et al. investigated organizational factors for occupational injury in a high-speed railway construction project and found that: Larger firms had a higher injury rate [27].

Most of the studies, except Bena et al., claimed that large firms have better OHS performance as they have more resources and have stronger capability of risk control [27,30-33]. However, this paper provides a contrary result.

To explain the results of small-sized firms' "better" performance and their perception disparity between design and construction teams, it is necessary to consider the potential disturbance from other kinds of subgroups (see Figures 3-5) and consider the distribution by project characteristics within each kind of contractor subgroup. From the perspective of project size, large-sized contractors tend to perform more large projects than small-sized ones. The data from large-sized contractors involve 16 respondents from small projects and 47 ones from large projects, while the data from small-sized 
contractors involve 36 ones from small projects and 46 ones from large projects. The subgroup of small-sized contractors has a higher small project rate. However, small projects tend to have worse OHS performance than large ones (see Table 1), and the significant perception disparity between design and construction teams exists only in large projects (see Figure 3). The perspective of project size distribution fails to explain the "better" performance and perception disparity of small-sized contractors.

From the perspective of project industry, the subgroup of small-sized contractors involves 48 data from power projects and 34 data from non-power projects, and the subgroup of large-sized contractors involves 45 data from power projects and 18 data from non-power projects. Large-sized contractors have a higher power project rate. The inefficiency of large-sized contractors discussed above and the complexity of power projects can explain the perception disparity between the two teams from large-sized projects. However, the lower power project rate of small-sized contractors can't explain the perception disparity between the two teams and the "better" performance of small-sized contractors.

From the perspective of project location, the distribution of the subgroup of small-sized contractors is: Southeast Asia (24), Islamic Area (21), Sub-Sahara Africa (21) and other regions (16). In the subgroup of large-sized contractors, it is: Southeast Asia (26), Islamic Area (7), Sub-Sahara Africa (15) and other regions (15). In the subgroup of medium-sized contractors, it is: Southeast Asia (1), Islamic Area (30) and Sub-Sahara Africa (36). Reviewing the small perception disparity of the two teams in Islamic Area and Sub-Sahara Africa (see Figure 5a,b), the region distribution can explain the small perception disparity between the two teams from medium-sized contractors (see Figure $6 \mathrm{~b}$ ). However, the perspective of project location distribution can't explain the results from small-sized contractors. The small-sized contractors performed more projects in Islamic Area and Sub-Sahara Africa, while the Q3 and Q4 perception in these regions is a little worse than that in Southeast Asia (see Table 1). This fails to explain why the small-sized contractors have a "better" performance.

In summary, the "better" performance and perception disparity of small-sized contractors are not attributable to the distribution disturbance from other kinds of subgroups. Bena et al. raised some potential causes when explaining the finding that large firms had worse OHS performance than small firms, such as under report of occupational injuries by small firms, types of ownerships of the contractors, different levels of worker training, working in the most dangerous stages for large contractors [27]. When comparing the results in Figure $6 a, c$, it is found that the design team from small-sized contractors has a similar perception of Q3 and Q4 with that from large-sized firms, while the perception of Q3 and Q4 from construction team in small-sized contractors is a little greater than that from large-sized firms. "Under report of occupational injuries by small firms" and "different levels of worker training" may provide an explanation for small-sized contractors "better" performance. Construction managers from small-sized contractors may display excessive optimism on their OHS performance, and tend to give a balloon score. A construction manager from a large-sized contractor confirmed their emphasis on OHS training and education, when describing their safety education in projects in Madagascar:

"When project managers arrived on the site, there was a three-day training about safety and health organized by local environmental engineers. We should pass the training test before job assignment. At the construction stage, (1) before work, we had 10 min safety education and had special training for different types of construction work; (2) during the work, there were supervisors reminding workers to wear masks and gloves; (3) after work, there was a review about the one day's work performance and the offenders would be criticized by name."

The training and education in small-sized contractors, by contract, is not so regular. The relatively low levels of training in small-sized contractors may cause the construction managers to inadequately identify the OHS issues. 


\section{Conclusions}

The paper investigated the perceived variation of OHS performance between design and construction teams of Chinese contractors working on international projects. Previous studies (e.g., from Zhao et al.; Marin et al.; Gyekye and Chen and Jin) have noticed that different people may perceive OHS in different ways $[10,11,14,19]$. Some scholars (e.g., Zhao et al., and Lingard et al.) found that design managers tend to have a higher perception of OHS risks than constructors $[10,12]$. However, there is a lack of research to explore whether design managers and construction managers evaluate OHS performance equally in international projects of Chinese contractors.

A comparative analysis was undertaken based on the data collected from 52 design managers and 160 construction managers from 16 Chinese contractors. The findings reveal that design and construction teams can have different evaluations of OHS performance and the assessment of OHS performance varies under different conditions. The findings indicate that the variation of OHS performance evaluation between design managers and construction managers is not only related to their different mental ways owing to professional disparity, but also can be mediated by their in-progress communication or affected by project and organizational conditions. Contractors are suggested to incorporate views from people with different occupations to achieve a comprehensive evaluation of OHS on sites.

The OHS performance of Chinese contractors in small projects is relatively poorer than the performance in large projects. The OHS performance of Chinese contractors in Islamic Area are perceived to be poorer than the performance in Southeast Asia and Sub-Sahara Africa. There is also significant difference between design and construction teams regarding the assessment of OHS performance in Southeast Asia. The findings suggest that the contractors should give greater emphasis on proactive OHS management instead of passively responding to external requirements. In addition, when delivering the more specialized projects, e.g., power projects, the contractors tend to have better performance on OHS management with regard to their rich experience in power construction. The contractors are suggested to pay more attention to the OHS management in newly-entered sectors.

It is also perceived that there is a lack of enough consideration of OHS requirements in design schemes in the international construction projects. As for the potential significant impact of design on OHS, scholars and practitioners should pay more attention to it.

There are also some limitations in this study. The four questions in this study only provided an overall assessment of OHS performance. Future research can incorporate more questions to provide detailed investigation of OHS across different aspects and stages during project delivery. This study only focused on the views from managers with different roles. Future research can combine the views of people with different management levels. In addition, we classified the project region according to geography, while some countries in the same region can have different economic, political or law conditions [29]. The results in this study just provided average OHS performances of Chinese contractors in the regions. Future studies can conduct more specific analyses with more data. The data used in the paper were of the respondents' perceptions that could be only partial reflections of their behaviors. Future research can conduct more direct observations and case studies to obtain a direct description of their behaviors. The paper also indicates research directions of how to integrate OHS management requirements and emphases of different teams, e.g., design and construction teams, during the project delivery, and how to balance the quality, time and cost of OHS management by using the method of multiple-criteria decision-making (MCDM) [34-37].

Author Contributions: Conceptualization: Z.L., W.T., C.F.D., L.Z., F.K.P.H., and R.Y.; data curation: Z.L.; formal analysis: Z.L., W.T., C.F.D., L.Z., and F.K.P.H.; funding acquisition: W.T.; investigation: Z.L.; methodology: Z.L., W.T., C.F.D., L.Z., F.K.P.H., and R.Y.; project administration: W.T.; resources: Z.L. and W.T.; software: Z.L.; supervision: W.T. and C.F.D.; validation: Z.L., W.T., C.F.D., L.Z., F.K.P.H., and R.Y.; visualization: Z.L.; writing—original draft: Z.L.; writing—review and editing: Z.L., W.T., C.F.D., L.Z., F.K.P.H., and R.Y. 
Funding: This research was funded by National Natural Science Foundation of China (grant nos. 51579135, 51379104, 51079070), State Key Laboratory of Hydroscience and Engineering (grant nos. 2013-KY-5, 2015-KY-5), and the Major Science and Technology Research Project of Power China (grant nos. DJ-ZDZX-2015-01-02, DJ-ZDZX-2015-01-07).

Conflicts of Interest: The authors declare no conflicts of interest.

\section{References}

1. Lu, W.; Ye, K.; Flanagan, R.; Jewell, C. Developing construction professional services in the international market: SWOT analysis of China. J. Manag. Eng. 2013, 29, 302-313. [CrossRef]

2. Zhao, Z.Y.; Shen, L.Y.; Zuo, J. Performance strategy of Chinese contractors in the international market. J. Constr. Eng. Manag. 2009, 135, 108-118. [CrossRef]

3. National Bureau of Statistics of China. China Statistical Yearbook; China Statistics Press: Beijing, China, 2016; ISBN 978-7503779176.

4. Reina, P.; Tulacz, G.J. The Top 250 International Contractors: Seeking Stable Markets. Available online: https: / / www.enr.com/articles / 40110-top-250-international-contractors-seeking-stable-markets?v=preview (accessed on 21 November 2018).

5. Tam, C.M.; Zeng, S.X.; Deng, Z.M. Identifying elements of poor construction safety management in China. Saf. Sci. 2004, 42, 569-586. [CrossRef]

6. Gurcanli, G.E.; Bilir, S.; Sevim, M. Activity based risk assessment safety cost estimation for residential building construction projects. Saf. Sci. 2015, 80,1-12. [CrossRef]

7. Wu, C.L.; Fang, D.P.; Liao, P.C.; Xue, J.W.; Li, Y.; Wang, T. Perception of corporate social responsibility: The case of Chinese international contractors. J. Clean. Prod. 2015, 107, 185-194. [CrossRef]

8. Zou, P.X.; Zhang, G. Comparative study on the perception of construction safety risks in China Australia. J. Constr. Eng. Manag. 2009, 135, 620-627. [CrossRef]

9. Rodrigues, F.; Coutinho, A.; Cardoso, C. Correlation of causal factors that influence construction safety performance: A model. Work 2015, 51, 721-730. [CrossRef] [PubMed]

10. Zhao, D.; McCoy, A.P.; Kleiner, B.M.; Mills, T.H.; Lingard, H. Stakeholder perceptions of risk in construction. Saf. Sci. 2016, 82, 111-119. [CrossRef] [PubMed]

11. Marin, L.S.; Cifuentes, M.; Roelofs, C. Results of a community-based survey of construction safety climate for Hispanic workers. Int. J. Occup. Environ. 2015, 21, 223-231. [CrossRef] [PubMed]

12. Lingard, H.; Zhang, P.R.; Blismas, N.; Wakefield, R.; Kleiner, B. Are we on the same page? Exploring construction professionals' mental models of occupational health safety. Constr. Manag. Econ. 2015, 33, 73-84. [CrossRef]

13. Gilkey, D.P.; del Puerto, C.L.; Keefe, T.; Bigelow, P.; Herron, R.; Rosecrance, J.; Chen, P. Comparative analysis of safety culture perceptions among homesafe managers workers in residential construction. J. Constr. Eng. Manag. 2012, 138, 1044-1052. [CrossRef]

14. Chen, Q.; Jin, R. A comparison of subgroup construction workers' perceptions of a safety program. Saf. Sci. 2015, 74, 15-26. [CrossRef]

15. Zhao, Z.Y.; Zhao, X.J.; Zuo, J.; Zillante, G. Corporate Social Responsibility for Construction Contractors: A China Study; Research Paper; Emerald Group Publishing Limited: Bingley, UK, 2016.

16. Casey, T.W.; Riseborough, K.M.; Krauss, A.D. Do you see what I see? Effects of national culture on employees' safety-related perceptions behavior. Accid. Anal. Prev. 2015, 78, 173-184. [CrossRef] [PubMed]

17. Ulubeyli, S.; Kazaz, A.; Er, B. Health safety perception of workers in Turkey: A survey of construction sites. Int. J. Occup. Saf. Ergon. 2014, 20, 323-338. [CrossRef] [PubMed]

18. Geminiani, F.L.; Smallwood, J.J.; Fee, S. A comparative analysis between contractors' inspectors' perceptions of the department of labour occupational health safety inspectorate relative to South African construction. Saf. Sci. 2013, 53, 186-192. [CrossRef]

19. Gyekye, S.A. Workers' perceptions of workplace safety: An African perspective. Int. J. Occup. Saf. Ergon. 2006, 12, 31-42. [CrossRef] [PubMed]

20. Louw, L.A.; Schaap, P. Categories of human risk factors which impact on the psychological fitness of construction workers: A review of the evidence. J. Psychol. Afr. 2013, 23, 589-599. [CrossRef] 
21. Zhang, R.P.; Pirzadeh, P.; Lingard, H.; Nevin, S. Safety climate as a relative concept: Exploring variability change in a dynamic construction project environment. Eng. Constr. Archit. Manag. 2018, 25, 298-316. [CrossRef]

22. Navidi, W.C. Statistics for Engineers Scientists; McGraw-Hill: New York, NY, USA, 2011; ISBN $978-0073401331$.

23. Nordlöf, H.; Wiitavaara, B.; Winblad, U.; Wijk, K.; Westerling, R. Safety culture reasons for risk-taking at a large steel-manufacturing company: Investigating the worker perspective. Saf. Sci. 2015, 73, 126-135. [CrossRef]

24. Weinstein, M.; Gambatese, J.; Hecker, S. Can design improve construction safety?: Assessing the impact of a collaborative safety-in-design process. J. Constr. Eng. Manag. 2005, 131, 1125-1134. [CrossRef]

25. Morrow, S.; Hare, B.; Cameron, I. Design engineers' perception of health safety its impact in the design process. Eng. Constr. Archit. Manag. 2016, 23, 40-59. [CrossRef]

26. Jannadi, M.O.; Assaf, S. Safety assessment in the built environment of Saudi Arabia. Saf. Sci. 1998, $29,15-24$. [CrossRef]

27. Bena, A.; Berchialla, P.; Debernardi, M.L.; Pasqualini, O.; Farina, E.; Costa, G. Impact of organization on occupational injury risk: Evidence from high-speed railway construction. Am. J. Ind. Med. 2011, 54, 428-437. [CrossRef] [PubMed]

28. Ju, C.; Rowlinson, S.; Ning, Y. Contractors' strategic responses to voluntary OHS programmes: An institutional perspective. Saf. Sci. 2018, 105, 22-31. [CrossRef]

29. Manu, P.; Mahamadu, A.M.; Van Manh, P.; Thuan The, N.; Ath, C.; Heng, A.Y.T.; Kit, S.C. Health safety management practices of contractors in South East Asia: A multi country study of Cambodia, Vietnam, Malaysia. Saf. Sci. 2018, 107, 188-201. [CrossRef]

30. Sunindijo, R.Y. Improving safety among small organisations in the construction industry: Key barriers improvement strategies. Procedia Eng. 2015, 125, 109-116. [CrossRef]

31. Hasle, P.; Limborg, H.J. A review of the literature on preventive occupational health safety activities in small enterprises. Ind. Health 2006, 44, 6-12. [CrossRef] [PubMed]

32. Fabiano, B.; Currò, F.; Pastorino, R. A study of the relationship between occupational injuries firm size type in the Italian industry. Saf. Sci. 2004, 42, 587-600. [CrossRef]

33. McVittie, D.; Banikin, H.; Brocklebank, W. The effects of firm size on injury frequency in construction. Saf. Sci. 1997, 27, 19-23. [CrossRef]

34. Akcay, C.; Aslan, S.; Sayin, B.; Manisali, E. Estimating OHS costs of building construction projects based on mathematical methods. Saf. Sci. 2018, 109, 361-367. [CrossRef]

35. Karakhan, A.A.; Rajendran, S.; Gambatese, J.; Nnaji, C. Measuring evaluating safety maturity of construction contractors: Multicriteria decision-making approach. J. Constr. Eng. Manag. 2018, 144, 04018054-1. Available online: https:/ / ascelibrary.org/doi/10.1061/\%28ASCE\%29CO.1943-7862.0001503 (accessed on 21 November 2018). [CrossRef]

36. Trinkuniene, E.; Podvezko, V.; Zavadskas, E.K.; Joksiene, I.; Vinogradova, I.; Trinkunas, V. Evaluation of quality assurance in contractor contracts by multi-attribute decision-making methods. Econ. Res. Ekon. Istraz. 2017, 30, 1152-1180. [CrossRef]

37. Zavadskas, E.K.; Turskis, Z.; Antucheviciene, J. Selecting a contractor by using a novel method for multiple attribute analysis: Weighted aggregated sum product assessment with grey values (WASPAS-G). Stud. Inf. Control 2015, 24, 141-150.

(C) 2018 by the authors. Licensee MDPI, Basel, Switzerland. This article is an open access article distributed under the terms and conditions of the Creative Commons Attribution (CC BY) license (http://creativecommons.org/licenses/by/4.0/). 